\title{
Anestesia perineural do membro pélvico de gatos (Felis domestica)
}

\section{The cats hindlimb perineural anesthesia (Felis domestica)}

Bianca Jacob Shimizu, ${ }^{\star}$ Duvaldo Eurides, ${ }^{\star \star}$ Francisco Cláudio Dantas Mota, ${ }^{\star}$ Eneida César Mastrantonio, ${ }^{\star}$ Patrícia Maria
Colleto Freitas, ${ }^{\star}$ Frederico Ozanam Carneiro e Silva ${ }^{\star *}$ Maria Clorinda Soares Fioravanti, ${ }^{\star \star \star *}$ Luiz Antônio Franda

\section{Resumo}

Em 15 gatos adultos, sem raça definida, machos e fêmeas, aparentemente sadios, realizou-se o bloqueio perineural do nervo isquiático, $1,0 \mathrm{~cm}$ distal ao trocanter maior do fêmur, entre os músculos bíceps femoral e vasto lateral. Na face medial da coxa, bloqueou-se o nervo femoral com o membro em abdução e flexão, cranial ao músculo pectíneo, próximo a artéria e veia femorais. Notou-se nos membros perda da sensibilidade cutânea e relaxamento muscular. $O$ método foi eficiente e de fácil aplicação para anestesia perineural de membros pélvicos de gatos sem raça definida.

Palavras-chave: gato; anestesia; nervo; cirurgia.

\begin{abstract}
In fifteen growh up cats without defined breed, males and females, seemingly healthy was done a perineural blockade of the isquiadic nerve, $1,0 \mathrm{~cm}$ farness to larger femur trocanter, beetwen the femoral and vasto lateral muscles. At the medial medial face of the thigt, the femoral nerve was blockaded with the limb in abduction and flexion, near to pectinuous muscle, cranial to femoral vessels. It was noticed on limbs, loss of sensibility and muscular relaxation. The metod was efficient and by easy aplication for perineural anaesthesia of hindlimb of cats without defined breed.
\end{abstract}

Keywords. cat; anesthesia; nerve; surgery.

\section{Introdução}

Foi verificado por Hodgson et al. (1998) que gatos submetidos a anestesia inalatória com isofluorano apresentam hipotensão e hipercapnia. Com halotano ocorre queda da pressão arterial e da freqüência respiratória (Grandy et al.,1989).

Animais portadores de alteração renal, quando submetidos a anestesia geral, podem apresentar necrose tubular aguda $e$ comprometimento circulatório, com conseqüente queda na perfusão renal e acúmulo de metabólicos tóxicos na urina (Mason, 1998).

A anestesia local pode ser indicada quando a anestesia geral representar um risco para a saúde do paciente, devido a sua baixa toxidade e fácil recuperação no pós-cirúrgico (Fialho, 1989). Em animais deprimidos e calmos, a anestesia local infiltrativa é eficiente para permitir reconstituição das extremidades dos membros torácicos e pélvicos (Slatter, 1998). Segundo Massone (1994), o cloridrato de lidocaína é um anestésico local potente, de rápida ação e de alta penetração nos tecidos. Associado a metomidina é eficaz para síntese de pele do membro posterior de cães (Sarkiala, 1998). Quando - membro pélvico de cães é anestesiado pelo método de Bier, permite reduzir a concentração de isofluorano, na cirurgia de amputação de falange (Web et al.,1999).

Raras são as citações sobre anestesia regional de membros pélvicos de gatos. Massone (1994) referiu a utilização do cloridrato de lidocaína a $2 \%$ para bloqueio neural dos membros torácicos e pélvicos. Oliveira (1970) referiu que em cães a anestesia local dos nervos radial, mediano, ulnar e musculocutâneo permite intervenções cirúrgicas no membro torácico. Eurides e Silva (1987) e Eurides et al. (1988) verificaram que o bloqueio dos nervos isquiático e femoral com lidocaína a $2 \%$ foi eficiente e possibilitou a realização de procedimentos cirúrgicos no membro pélvico de cães.

O nervo isquiático recebe fibras dos ramos ventrais do sexto e sétimo nervos lombares e primeiro nervo sacral e deixa a cavidade pélvica através do forame isquiático maior, situando-se entre o músculo piriforme e glúteo profundo. Emite ra\footnotetext{
* Médicos-veterinários. Alunos do mestrado em Ciências Veterinárias - Clínica e Cirurgia. Faculdade de Medicina Veterinária/FAMEV. Universidade
Federal de Uberlândia/UFU/MG. biancashimizu@ @otmail.com ** Médicos-veterinários. Professores titulares. Faculdade de Medicina Veterinária. Universidade Federal de Uberlândia/UFU. Av. Pará 1720. Campus
Umuarama. 38400-902. Uberlândia, MG. Brasil.

*** Médicos-veterinários. Professores adjuntos. Escola de Veterinária. Universidade Federal de Goiás.
} 
mos para os músculos gêmeos e quadrado da coxa, segue sobre o tendão do músculo obturador interno e inerva os músculos bíceps da coxa, semitendinoso e semimembranoso. O nervo desce na coxa entre a tuberosidade isquiática e o trocanter maior do fêmur, ao longo da superfície lateral do músculo adutor e músculo semimembranoso. Emite ramificação para o músculo abdutor crural caudal e nessa região, ramifica-se nos nervos fibular e tibial. O nervo femoral é formado pelos ramos ventrais do quinto e sexto nervos lombares. Corre ventralmente em direção ao membro pélvico e, após inervar o músculo quadríceps femoral, continua como nervo safeno. Nervo isquiático tem a função de inervar os músculos que provocam extensão e flexão dos dedos, e o nervo femoral de flexionar o quadril e estender o joelho (Getty, 1986).

Como os anestésicos gerais põem em risco a vida dos animais e devido a inúmeras cirurgias realizadas em membros pélvicos de gatos, é proposto neste experimento avaliar a eficácia da anestesia perineural dos nervos isquiático e femoral de gatos sem raça definida.

\section{Material e métodos}

Foram utilizados 15 gatos adultos, sem raça e idade definidas, aparentemente sadios, de ambos os sexos e peso variando de 2,5 a $5,4 \mathrm{~kg}$, para anestesia perineural dos nervos isquiático e femoral com cloridrato de lidocaína a $2 \% \mathrm{com}$ epinefrina, ${ }^{1}$ na dose de $3,0 \mathrm{mg} / \mathrm{kg}$, por bloqueio. Os animais foram submetidos a tricotomia na região inguinal e lateral da coxa, próximo ao trocanter maior do osso fêmur e antisepsia com álcool e polivinilpirrolidona. ${ }^{2} \mathrm{Na}$ face lateral da coxa, $1,0 \mathrm{~cm}$ distalmente ao trocanter maior do fêmur, entre os músculos bíceps femoral e vasto lateral, foi administrado o anestésico para bloqueio do nervo isquiático. $\mathrm{Na}$ face medial, com o membro abduzido e flexionado, fezse o bloqueio do nervo femoral cranialmente ao músculo pectíneo, próximo à artéria e veia femorais (Figura 1).

Após administração do anestésico, verificaramse o início dos sintomas, a área anestesiada, duração da anestesia e ação motora do membro. $A$ área de sensibilidade foi determinada com pinça de dissecação com dente de rato e agulha hipodérmica.

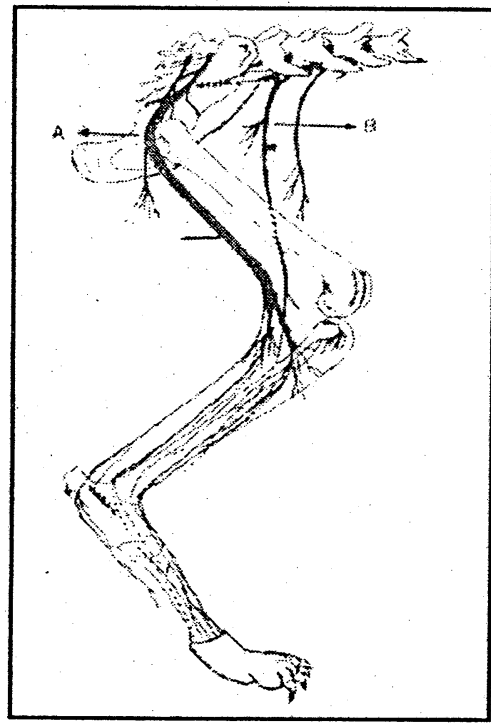

Figura 1: Representação esquemática do membro pélvico direito de gato. Notase o local do bloqueio anestésico dos nervos isquiático $(A)$ e femoral $(B)$.

\footnotetext{
1 Xylocaina. Astra Quimica do Brasil, São Paulo, SP.

${ }^{2}$ Laboridine. Glicobar Industria Farmacêutica. Ribeirão Preto, SP.
}

\section{Resultados e discussão}

Os locais onde a anestesia foi efetiva corresponderam às áreas cutâneas insensiveis e dos músculos inervados pelos nervos isquiático e femoral, de acordo com os limites anatômicos determinados por Getty (1986), e no bloqueio anestésico dos nervos isquiático e femoral descritos em cães (Eurides e Silva, 1987) e ovinos (Silva et al., 1994). A média e desvio-padrão(s) da perda da ação motora e insensibilidade foram de 15 minutos e $s=4,4827$, não sendo verificada rápida ação do anestésico como referido por Massone (1994). A média do início do efeito máximo da anestesia foi de $27 \mathrm{minu}$ tos e $s=4,0355$, que permaneceu por tempo médio de 46 minutos com $s=5,0709$. Decorrido este período, notou-se manifestação do retorno da sensibilidade e coordenação motora e os animais se recuperavam em média aos $90 \mathrm{mi}$ nutos e $s=6,4475$, do início da anestesia (Tabela 1, Figura 2). As variações entre os períodos de anestesia em cada animal ocorreu provavelmente devido à diferença na constituição física local entre os animais.

Tabela 1: Anestesia perineural dos membros pélvicos de gatos. Média e desvio-padrão ( $\mathrm{min}$ ) do início dos sintomas, perda da sensibilidade, duração da anestesia e recuperação dos animais. Uberlândia, 2001

\begin{tabular}{ccccc}
\hline Animais & $\begin{array}{c}\text { Início dos } \\
\text { sintomas }\end{array}$ & $\begin{array}{c}\text { Perda da } \\
\text { sensibilidade }\end{array}$ & Duração & Recuperação \\
\hline 1 & 15 & 27 & 45 & 90 \\
2 & 21 & 30 & 55 & 105 \\
3 & 10 & 14 & 45 & 81 \\
4 & 15 & 29 & 45 & 85 \\
5 & 18 & 30 & 47 & 95 \\
6 & 14 & 25 & 46 & 90 \\
7 & 13 & 28 & 40 & 90 \\
8 & 10 & 25 & 45 & 85 \\
9 & 14 & 28 & 40 & 82 \\
10 & 12 & 27 & 36 & 85 \\
11 & 18 & 28 & 50 & 92 \\
12 & 13 & 25 & 46 & 88 \\
13 & 18 & 30 & 48 & 92 \\
14 & 19 & 30 & 55 & 100 \\
15 & 15 & 29 & 47 & 90 \\
\hline Médias & 15 & 27 & 46 & 90 \\
\hline DP & 4,48 & 4,04 & 5,07 & 6,44 \\
\hline
\end{tabular}

$\mathrm{DP}=$ desvio-padrão

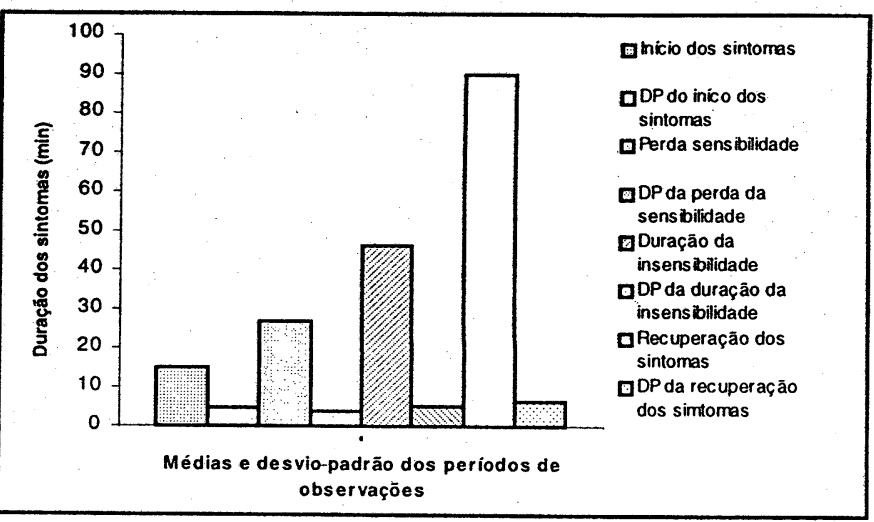

Figura 2: Média e desvio-padrão da duração dos sintomas e períodos de observação após anestesia perineural dos nervos isquiático e femoral dos membros nélvicos de gatos sem raça definida. 
Complicações como hipotensão, hipercapnia e necrose tubular após anestesia geral foram observadas em cães e gatos (Hodgson et al., 1998, Mason, 1998, Slatter, 1998). Pacientes portadores de alterações cardiacas, renais ou hepáticas requerem cuidados especiais em procedimentos anestésicos, devido ao alto risco da anestesia geral (Daleck et al., 1992).

Durante a anestesia geral pode ocorrer hipoventilação ou hiperventilação, taquipnéia, hipotensão e disritmias (Slatter, 1998). Foram verificadas alterações cardiovasculares em animais submetidos a anestesia inalatória, intravenosa e dissociativa (Bernis e Lazzeri, 1957). A anestesia epidural lombar para cães pode ocasionar queda da pressão sangüínea e insuficiência da perfusão capilar (Hall, 1970).

No entanto, na literatura consultada não foram encontradas citações sobre anestesia perineural do membro pélviço de gatos impossibilitados de serem submetidos a anestesia geral. $O$ método proposto neste experimento, de ocasionar bloqueio dos nervos isquiático e femoral, não apresentou complicações durante e após a anestesia. A segurança observada deveu-se, provavelmente, à baixa toxidade do cloridrato de lidocaína (Fialho, 1989).

Oliveira (1970) promoveu em cães bloqueio anestésico dos nervos radial, mediano, ulnar e musculocutâneo, sendo eficiente para realização de cirurgias no membro torácico. No entanto, foi necessária a administração do anestésico em quatro locais diferentes. Neste experimento, o bloqueio dos nervos isquiático e femoral foi suficiente para causar perda da ação motora e da sensibilidade da maior parte do membro pélvico. Os resultados obtidos deveram-se ao bloqueio realizado antes das ramificações dos nervos para o membro (Getty, 1986), permitindo a anestesia da maioria dos músculos do membro pélvico (Figura 1).

A lidocaína é um anestésico local de alta potência, de rápida ação e de grande poder de penetração nos tecidos (Massone, 1994), e na concentração de $2 \%$ é indicada para anestesia perineural (Fialho, 1989). Na administração de 3,0mg/kg para cada bloqueio anestésico, utilizada neste trabalho, os animais permaneciam ativos, uma vez que não receberam medicação pré-anestésica e recuperavam sem sintomas aparentes de intoxicação.

Nervo isquiático tem a função de inervar os músculos que provocam extensão e flexão dos dedos, e o nervo femoral de flexionar o quadril e estender o joelho (Getty, 1986). Com bloqueio destes nervos, os gatos mantinham-se em decúbito lateral ou com a perna e pé apoiados sobre o solo, provavelmente devido ao desconforto e a falta de apoio. Quando locomoviam, arrastavam a superfície dorsal da pata e em pé mantinham o dorso da pata em contato com o solo, sem suportar o peso do corpo, observações coincidentes com as verificadas em cães por Eurides e Silva (1987). Após o término do efeito anestésico, os animais recuperaram a capacidade motora sem complicações.

A anestesia perineural dos membros pélvicos de cães e ovinos, com cloridrato de lidocaína a $2 \%$ com adrenalina, promove anestesia de quase todo membro, exceto na região inervada pelo nervo obturador (Eurides e Silva, 1987; Silva et al., 1994). Observações coincidentes com as verificadas nes- te experimento (Figura 3). Isto porque o nervo obturador provém dos ramos ventrais de $L 5$ e $L 6$ e inerva os músculos obturatores, adutor, pectíneo e grácil (Getty, 1986).

Com o bloqueio anestésico do nervo isquiático e femoral, os gatos apoiavam a face plantar do pé, se locomoviam com desequilibrio e apresentavam movimento de abdução do membro anestesiado. Fato também notado em cães por Eurides e Silva (1987) e Eurides et al. (1988) e em ovinos por Silva et al. (1994), devido a maioria dos músculos do membro pélvico serem inervados pelos nervos isquiático e femoral. $O$ movimento de abdução observado durante a locomoção ocorreu porque os músculos inervados pelo nervo obturador não sofreram ação do cloridrato de lidocaína.

Para a anestesia do membro pélvico de cães, com o bloqueio dos nervos isquiático e femoral Eurides e Silva (1987), administraram-se $3,5 \mathrm{ml}$ de cloridrato de lidocaína para cada nervo anestesiado. Utilizando a mesma técnica em ovinos Silva et al. (1994), aplicaram 5,0ml para cada bloqueio. Neste experimento, administração de $3,0 \mathrm{mg} / \mathrm{kg}$ de lidocaína a $2 \%$ para cada nervo, mostrou-se eficaz por promover perda da ação motora e insensibilidade das estruturas invervadas pelos nervos isquiático e femoral de forma lenta e gradativa.

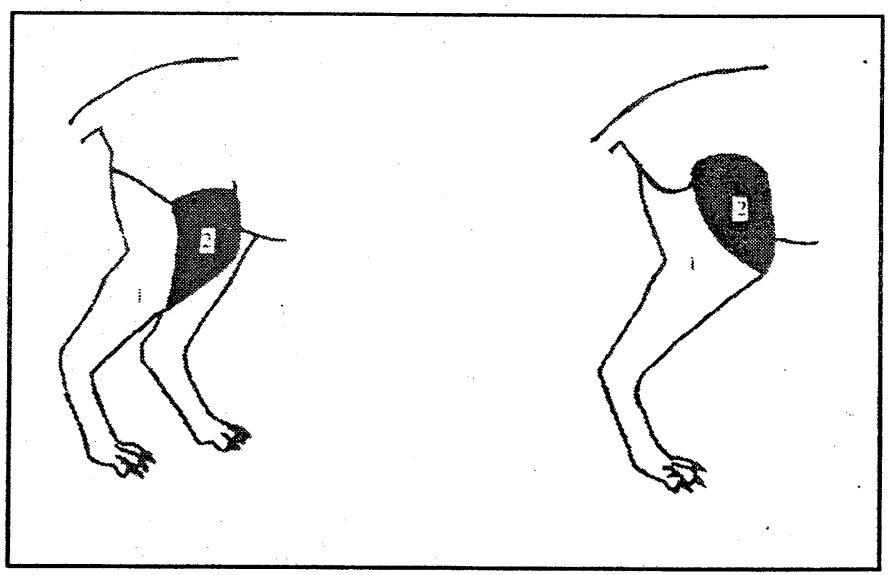

Figura 3: Representacão esquemática das áreas insensibilizadas da face lateral (A) e medial (B) do membro pélvico de gato submetido ao bloqueio do nervo isquiático (1) e femoral (2).

\section{Conclusões}

A anestesia do nervo isquiático e femoral em gatos com cloridrato de lidocaína a $2 \%$ com adrenalina é eficiente, de fácil aplicação e não ocasiona complicações na recuperação da sensibilidade e ação motora do membro pélvico.

$\mathrm{O}$ bloqueio dos nervos isquiático e femoral promove a anestesia do membro pélvico, com exceção das estruturas inervadas pelo nervo obturador.

A média de duração da perda de ação motora e da insensibilidade é de 46 minutos e, decorridos 90 minutos do início da anestesia, os pacientes recuperam a ação motora do membro. 


\section{Referências}

BERNIS, W. O., LAZZERI, L. Anestesia de cão pelo pentobarbital sódico. Arq. Esc. Sup. Vet., v. 10, p. 15, 1957.

DALECK, C. R., BAPTISTA, L. C., MUKAI, L. S. Tópicos em cirurgia de cães e gatos. Jaboticabal: FUNEP, 1992.

EURIDES, D., SILVA, F. O. C. Anestesia do membro pélvico de cão. Estudo experimental. Arq. Flum. Med. Vet., Rio de Janeiro, v. 7, n. 2, p. 19-22, 1987.

EURIDES, D., KAYANO, M. N., SILVA, F. O. C. Anestesia dos nervos isquiático e femoral nas intervenções cirúrgicas de cães. Rev. Centro Ciências Rurais, Santa Maria, v. 18, n. 1, p. 75-79, 1988.

FIALHO, S A. G. Anestesiologista veterinária. 2. ed. São Paulo: Nobel, 1989.

GETTY, R. Sisson/Grossman-Anatomia dos animais domésticos. 5. ed., Rio de Janeiro: Guanabara Koogan, 1986.2000 p.

GRANDY, J.L., HODGSON, D. S., DUNLOP, C. I., CURTIS, C. R., HEATH R. B. Cardipulmonary effects of halotane anesthesia in cats. Am. J. Vet. Res., Chicago, v. 50, n. 10, p. 29-32, 1989.

HALL, L. W. Anestesia e analgesia veterinária. 2. ed. Zaragosa: Acribia 1970

HODGSON, D. S., DUNLOP, C. I., CHAPMAN, P. L., GRANDY, J. L. Cardiopulmonary effects of anesthesia induced and mantained with isofluorane in cats. Am. J. Vet. Res., Chicago, v. 59, n. 2, p. 182-185, 1998.

MASON, D. E. nestesia e o sistema urinário. In: SLATTER, D. Manual de cirurgia de pequenos animais. São Paulo: Manole, 1998. Cap. 167. p. 2671-2676.

MASSONE, F. Anestesiologia veterinária. 2. ed. Rio de Janeiro: Guanabara Koogan, 1994.250 p.

OLIVEIRA, H. P. Contribuição para anestesia do membro torácico do cão. Belo Horizonte-MG. 40 p. Dissertação (Mestrado em Clínica e Cirurgia). Escola de Veterinária, Universidade Federal de Minas Gerais, 1970.

SARKIALA, E. Suturations of wounds of extremities in dogs using medetomidine as sedative and analgesic drugs. Ac. Vet. Scand., Finland v. 85, n. 2, p. 175-177, 1998.

SILVA, F.O.C.,PEREIRA, C.C.H., EURIDES, D., XAVIER, G. C., SEVERINO R.S., BOMBONATO, P.P., DRUMMOND, S. S., SANTOS, A. L. Q. Anestesia do membro pélvico de ovinos. Estudo experimental. Rev. Fac. Zootec. Vet. Agron., Uruguaiana, v. 1, n. 1, p. 5-10, 1994.

SLATTER, D. Manual de cirurgia de pequenos animais. 2. ed. São Paulo: Manole, 1998. 2830p.

WEB, A. A., CANTWELL, S. L., DUKE, T., ADKINS, E. Intravenous regional anesthesia (Bier block) in a dog. Can. Vet. J., Ottawa, v. 40, n. 6 p. 419-421, 1999. 